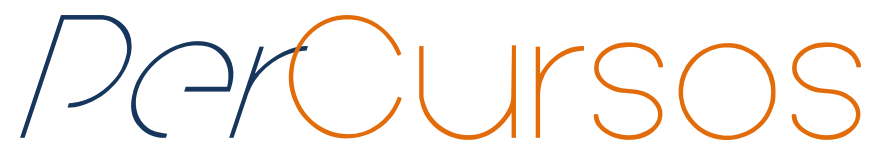

\title{
PROFHISTÓRIA, experimento sem prognóstico
}

\begin{abstract}
Resumo
O texto discorre sobre a criação do Mestrado Profissional em Ensino de História (PROFHISTÓRIA) relacionado a fatores gerais e específicos de contexto histórico. De forma ensaística, aqui são levantadas hipóteses que apontam para precedentes da criação do programa em 2013 cogitando que ele pontifica práticas experimentadas em cursos de História antes mesmo de sua criação, práticas às quais o programa dá forma e institucionalidade. Sugere que o PROFHISTÓRIA seja uma reação a uma conjuntura crítica desfavorável na área de História e que seus resultados futuros e possíveis conquistas possam expressar reivindicações e anseios por mudanças mais amplas na área do que aquelas explicitadas por ocasião de sua criação.
\end{abstract}

Palavras-chave: História. Ensino de História. Cursos de História. Identidade Profissional.

\section{Bruno Flávio Lontra Fagundes} Doutor em História pela Universidade Federal de Minas Gerais - UFMG. Professor da Universidade Estadual do Paraná - UNESPAR.

Brasil

parabrunos@gmail.com

\section{Para citar este artigo:}

FAGUNDES, Bruno Flávio Lontra. PROFHISTÓRIA, experimento sem prognóstico. Revista PerCursos, Florianópolis, v. 18, n.38, p. 33 - 62, set./dez. 2017.

\section{DOI: $10.5965 / 1984724618382017033$}

http://dx.doi.org/10.5965/1984724618382017033 


\title{
PROFHISTÓRIA, Experiment without prognosis
}

\begin{abstract}
The text discusses the creation of the Professional Master's Degree in History Teaching (PRO-FHISTÓRIA) related to general and specific context factors. In an essay, hypotheses that point to precedents of the creation of the program in 2012 are raised, reasoning that it pontificates practices experienced in history courses even before its creation, practices to which the program gives form and insti- tutionality. It suggests that PROFHISTÓRIA is a reaction to an unfavorable critical conjuncture in the area of History and that its future results and possible achievements can express demands and longings for wider changes in the area than those made explicit at the time of its creation.
\end{abstract}

Keywords: History. History Teaching. History Courses. Professional Identity. 


\section{Introdução}

Os primeiros resultados do PROFHISTÓRIA na forma de dissertações estão começando a aparecer. Para além da qualidade de muitos trabalhos e de sua fidelidade àquilo a que se propõe o programa, decerto há motivos e motivações para a criação de um programa de Mestrado Profissional nacional em História numa dada conjuntura histórica dos cursos de História, numa conjuntura da história da História que não se resume a ser derivada de uma discussão epistêmica. É o que aponto aqui como hipótese. É indispensável verificar fatores de contexto conexos, coetâneos e contemporâneos à criação do PROFHISTÓRIA em 2013 - com primeira turma em 2014.

O pensamento sobre as motivações para a criação do PROFHISTÓRIA não pode se ater à crença de que a mera mudança de formação profissional, sem mudanças na escola, seja capaz de ocasionar grandes efeitos. Um movimento necessário é verificar como uma alteração de formato de curso de História não só problematiza questões ligadas à formação continuada de professores de História, mas, em linha direta, equaciona relações entre universidade e escola, entre egressos de cursos de História e outros destinos profissionais que não se restringem à docência. Um dos objetivos deste texto é ensaiar uma avaliação sobre se a criação do PROFHISTÓRIA não resulta de processos que vão além da História matéria escolar.

Este texto tem um corte ensaístico. Alguns dados são inferidos, embora combinados a dados apurados, com o que algumas proposições são feitas a título de hipóteses.

Numa situação em que se discute a função do historiador, quando despontam no país debates sobre uma História Pública que toma como argumento um distanciamento de historiadores de outros públicos sociais que desejam história e não a encontram diretamente vindos da universidade, a escola parece ressurgir como espécie de reserva de público cativo, que não abandonará a História. 


\section{História e anseios profissionais: sobre o contexto do PROFHISTÓRIA}

O sentido da proposta de mestrados profissionais na área de História pode, por hipótese, estar articulado a anseios expressos por praticantes da área manifestados em frases como: "e agora, onde vou trabalhar?" e o que, de fato, cursos fazem para ajudar a viabilizar isso. Algumas vezes assinados por acadêmicos, textos sem pretensão reproduzidos em fóruns de discussão de redes sociais fazem proposições pertinentes ao debate, quando se verificam alguma desconfiança de historiadores quanto às saídas propostas para o impasse. Jurandir Malerba se dirige aos historiadores recalcitrantes ao debate sobre o repensar a missão do historiador no "cenário brasileiro".

Compete-nos suprir uma gigantesca demanda reprimida por qualificação. Carecem de capacitação os jovens historiadores abertos às novas faces do mercado, nas instituições públicas e privadas ligadas à preservação da memória e patrimônio, ao lazer e tempo livre, à mídia e novas tecnologias e linguagens de comunicação e mesmo ao business. Sobretudo, precisamos qualificar os historiadores que estão lá na ponta, na sala de aula, na nobre e difícil missão de educar jovens cidadãos brasileiros. Foi-se o tempo de Ranke, Braudel, Sérgio Buarque, de teses como O Mediterrâneo e Visões do Paraíso. É hora e vez de repensarmos nossa missão no cenário brasileiro. O mestrado profissional poderá ser $\mathrm{O}$ caminho para o fortalecimento da área e do país. (MALERBA, 2012)

Faz-se necessário verificar problematizações em que a própria corporação historiadora universitária se coloca - corporação de corte excessivamente acadêmico, a se lembrar da formação de nossa índole histórica no início de nossas universidades, que abrigavam cursos de História por meio do recrutamento de professores em grêmios literários, círculos de sábios e sociedades de recreação intelectual de homens de letras.

Precisam ser verificados movimentos e iniciativas que têm revisado e questionado, há pelo menos duas décadas no Brasil, o pensamento sobre cursos de História e os dilemas profissionais a que conduzem seus egressos. O PROFHISTÓRIA pode ser pensado como encaminhamento de uma saída inédita para a resolução de problemas da área de História que vão muito além de entrosar a relação escola-universidade. Ainda mais em se 
sabendo que fazer um programa de formação continuada inovador, sem se mexer na escola, parece inócuo. Por mais bem elaborada que seja a formação.

Em 2010, em entrevista à Revista Mosaico, do corpo discente do Programa de PósGraduação em História, Política e Bens Culturais (PPHPBC) do CPDOC/FGV, Luciano Figueiredo, historiador e então diretor da Revista de História da Biblioteca Nacional, fazia um balanço do sucesso da revista, relacionando-o com o que considerava o "momento atual do campo histórico". Indicava que a História de e para especialistas oferecida nos cursos universitários "tendeu a produzir uma forma de exposição própria que passou a ser difundida, ensinada e emulada por aqueles que se preparam para a profissão", embora tenha "abdicado do estilo em nome da forma" em linguagem acadêmica que prevê leitores prévios formados. Espaços públicos de debate histórico, dizia Figueiredo, se "encolheram para as salas de aulas, congressos e publicações" restritas, calhando numa situação de "poucas condições para a fruição da leitura", ligando História com a "figura pública do historiador" e com o que identificava como mudança de "nossa cultura profissional”. Seu diagnóstico da área histórica era otimista e articulava apresentação da história com meios pouco usuais.

(...) Se estivermos abertos para formas diferenciadas de produzir discursos, as velhas e novas mídias oferecem alternativas formidáveis. Basta acompanhar os programas de história no rádio - como vem sendo feito na UFMG - e nos programas de TV (como o "De lá para cá", na TV Brasil) ou acompanhar alguns sites (dentre vários posso mencionar o “Café História”) e blogs. (FIGUEIREDO, 2010, p.98)

Figueiredo enfatizava a convivência profissional significativa de historiadores e jornalistas na redação da Revista de História da Biblioteca Nacional. Componente significativo do contexto histórico de criação do PROFHISTÓRIA, não só porque atraía o interesse de historiadores acadêmicos para a iniciativa da revista, mas ainda agregava reflexões em torno das possibilidades de cursos oferecerem formação diversificada, visando alternativas de escolhas de atuação profissional além da docência. 
Quanto às restrições de atuação profissional que desafiam a carreira dos historiadores, hoje, sugiro que um encaminhamento poderia ser o de conceber a História como atividade de produção científica e de participação sociocultural. É importante verificar que isso já está acontecendo em muitos cursos no país, para o que critérios de avaliação de qualidade cultural devem ser criados.

Alguns cursos de História brasileiros elaboram indicadores de impactos e de resultados de seus projetos institucionais, fazendo avaliação regularmente. Dizia a mim uma das coordenadoras de curso com quem falei, em pesquisa realizada em 2012: "Temos a convicção de que proporcionamos uma formação com um olhar muito voltado para o plural, para a diversidade e para as diferentes possibilidades de atuação profissional”. (FAGUNDES, 2015, p.176). ${ }^{1}$

\section{O contexto geral que provavelmente influiu na criação do PROFHISTÓRIA}

O PROFHISTÓRIA foi criado num contexto que ainda não mudou, em que acontecimentos têm trazido questionamentos ao fazer e ser da História, não obstante as proclamações de ser área de conhecimento consolidada em longa tradição.

É importante frisar, de saída, um condicionamento geral: um contexto de licenciaturas em crise $^{2}$ com não poucas reivindicações por mudanças no caráter da formação profissional de cursos de licenciaturas, emuladas por angústias profissionais derivadas de ter de lidar com uma outra escola por outros meios, mas também pelo fator “empregabilidade” na área. Muitos egressos dos cursos de História não veem situações de emprego para além de poucos concursos de nível superior de altíssima concorrência, numa situação desestimulante de emprego na desvalorizada Escola Básica.

\footnotetext{
${ }^{1}$ Esse depoimento foi recolhido no bojo de pesquisa que realizei pela Web entre os dias 20 de abril e 10 de junho de 2012. Ao todo, levantei 205 sites de cursos de História no Brasil e obtive retorno de professores/coordenadores de aproximadamente 40 instituições. Visei subsidiar comunicação no Encontro Estadual da ANPUH MG em 2012, como de fato ocorreu. Versava sobre o estado da arte de cursos de História brasileiros pelos textos de Apresentação dos cursos em instituições de ensino superior do Brasil, fixados em sites, e sobre informações dos cursos dadas a mim por consulta a coordenadores via mailing. De minha pesquisa, resultou texto publicado em Revista Saeculum. Ver FAGUNDES, 2015. Aqui, quando a referência registrar " $A$ " entenda-se que não são palavras do coordenador ou professor, mas trecho de textos de Apresentação on line do curso.

${ }^{2}$ Ver, especialmente, SOUZA, 2011 e AMORIM, 2014.
} 
A pesquisadora Marina Amorim analisou os egressos da turma 1998-2001 do Curso de História da UFMG, apurando em que egressos, hoje, trabalham, se trabalham com História, advertindo que a realidade do curso não constitui caso isolado na UFMG. Destaca a autora "a queda brusca da procura por todos os cursos de licenciatura da UFMG no vestibular, um grande sinal do pouco interesse pela profissão docente" (AMORIM, 2014, p.54/55). No ano de 2000, "dos 17 cursos mais concorridos, seis formavam professores", porém em 2012, dos 15 mais concorridos cursos da universidade não há nenhum curso de licenciatura. Dados alarmantes rondam a realidade do professor, quando constata-se que a relação candidato-vaga, nos "cursos de Ciências Biológicas, Educação Física, Geografia, História, Letras, Matemática e Pedagogia [da UFMG] caiu, em dez anos, de 12 a 15 candidatos por vaga para 1,4 a 4,8 candidatos por vaga" (AMORIM, 2014, p.56). Além da queda dos níveis salariais, para Souza, o valor simbólico do diploma também despencou (SOUZA, 2011) e com ele o emblema do que seria a "venerável figura do mestre". Analisando a USP, Leme (apud AMORIM, 2014) aponta na mesma direção para a universidade paulista: "a generalizada queda da concorrência nos cursos de licenciatura é forte evidência de que há pouco interesse pela docência atualmente". (SOUZA, 2011).

Outro componente de contexto da criação do PROFHISTÓRIA não pode ser jamais esquecido: o projeto de lei de criação da profissão de historiador.

O processo da regulamentação da profissão também endossa o anseio daqueles que pensam nas lacunas de sua formação para um mercado de trabalho presumidamente aquecido com oportunidades novas de trabalho, para as quais os cursos de História, de modo geral, não formam numa extensão em que se possa conceber como formador para alguma atividade profissional para além da docência. As iniciativas eram - segundo pesquisa em 2012 - realizadas à margem do desenho institucional consagrado de formação para docência. Embora alguma preparação, em disciplinas isoladas que não alteram a missão do curso, ofereçam algum conhecimento sobre mídias, patrimônio, museus. Tendo em vista a institucionalização da figura do historiador, ela poderia criar alternativas à atuação docente, embora estas oportunidades estejam sendo conquistadas 
por outros profissionais que falam do passado: jornalistas, webdesigners, documentaristas, entre alguns outros.

É do ano de 2009 um dos momentos mais agudos da discussão sobre a iniciativa, sem firmá-la como tendo início naquele ano.

Naquele ano era apresentado ao Congresso Nacional o Projeto de Lei 368, do Senado Federal, pela criação da profissão. A justificativa do projeto firmava um historiador reconfigurado, de perfil e de habilidades que não se encaixavam em certa representação erudita de historiadores e de seu fazer e ofício representada na academia histórica. Quando chamado a opinar sobre o que achava da regulamentação da profissão de "historiador", Bruno Leal advertia:

(...) Vi muitas reportagens que entrevistavam grandes nomes da historiografia que eram contra a regulamentação (ou o projeto, especificamente). Ótimo. Acho justíssimo. E muitas dessas opiniões eram muito boas. Colocaram-me em dúvida em alguns momentos. Mas esses profissionais já estão muito bem inseridos no mercado de trabalho. Não vi quase nenhuma matéria em que se entrevistasse, por exemplo, um recém-formado em História, ou, ainda, um jovem historiador desempregado. (LEAL apud FAGUNDES; HAHN, 2014, p.22)

A justificativa do projeto previa um historiador cuja atividade não se restringia mais ao exercício do magistério - básico ou superior. Mesmo sendo citação longa, convém registrar.

O campo de atuação do historiador não tem se restringido mais à sala de aula, tradicional reduto desse profissional. Sua presença é cada vez mais requisitada não só por entidades de apoio à cultura, para desenvolver atividades e cooperar, juntamente com profissionais de outras áreas, no resgate e na preservação do nosso patrimônio histórico, mas também por estabelecimentos industriais, comerciais, de serviço e de produção artística (...) No âmbito industrial, o historiador vem trabalhando na área de consultoria sobre produtos que foram lançados no passado, para análise de sua trajetória e avaliação sobre a viabilidade de seu relançamento no mercado consumidor, ou ainda, para o estudo das causas de seu sucesso ou fracasso (...) Pelas suas qualificações, o historiador é imprescindível para os estabelecimentos do setor de 
turismo, que contratam seus serviços para desenvolver roteiros turísticos para visitação de locais com apelo histórico e cultural (...) Entidades públicas e privadas recorrem ao historiador para recolherem e organizarem informações para publicação, produção de vídeo e de CDROM, programas em emissoras de televisão, exposições, eventos sobre temas de história... Não menos valiosa é a sua colaboração nas artes, onde o historiador faz pesquisa de época para os produtores de teatro, cinema e televisão, quer auxiliando na elaboração de roteiros, quer dando consultoria sobre os cenários e outros elementos da produção artística. No mundo onde a qualidade e a excelência de bens e serviços vêm se sofisticando cada vez mais, os historiadores devem ter sua profissão regulamentada, pois seu trabalho não mais comporta amadores ou aventureiros de primeira viagem. (BRASIL, Senado Brasileiro, 2012.)

Após emendas sofridas, as justificativas continuavam a manter suas aferições de potencialidades de atuação profissional, mas iam além, preocupadas com o incremento da vontade por cursos de História, como quis a justificativa da emenda da senadora Vanessa Graziotin. “Essa regulamentação vai tornar os cursos de História mais atraentes, melhorando o perfil dos candidatos ao exercício desta profissão. E irá facilitar o acesso dos formandos ao mercado de trabalho, abrindo horizontes e espaços profissionais para os historiadores". (BRASIL, Senado Brasileiro, 2012. grifo meu)

A justificativa da senadora era expressiva do pensamento da sociedade sobre o profissional de História como docente, pensamento provavelmente formado em função de consolidado conceito de que profissional de História é professor, e em vista do que são o ensino da disciplina, seus lugares de aprender e ensinar, - os seus campos de atuação reconhecidos - que, com o projeto poderiam se ampliar, como imaginava a senadora, que compartilhava com o público em geral certa imagem acadêmica erudita da História como algo intrinsecamente inacessível à grande parte, e que o projeto poderia vir a reverter.

Se o contexto geral contém componentes que influíram provavelmente na iniciativa da criação do PROFHISTÓRIA, necessário é, ainda, verificar o contexto particular de discussões e iniciativas que há alguns anos marcam o debate entre historiadores, dentro de seus cursos, sobre seus cursos e sobre o futuro da profissão. Depois, verificar 
muitas práticas adotadas dentros dos cursos que pouco são salientadas, embora já sejam usuais neles.

\section{Historiadores: o que já discutem em seus encontros e já fazem em seus}

\section{cursos há alguns anos}

Se retomarmos o tema de Encontros estaduais de História, da ANPUH, desde pelo menos 2010, encontraremos alguns com o teor de discussão sobre o próprio campo de saber e suas conexões conceituais e sociais. ${ }^{3}$

Em 2010, a ANPUH Pernambuco convocava para o tema "o ofício do historiador e os novos territórios da História" (grifo nosso), enquanto em Santa Catarina a seção estadual discutia tema coagente, sobre a própria História em "História: desafios para o tempo presente”. Em 2012, no Ceará, historiadores abriam-se para discutir para que serve a história, e para quem ela deveria se dirigir, em "Comunidades e identidades: História (s) para que(m)?" Ainda em 2012, enquanto a seção paraibana debatia-se com a relação entre história e sociedade, confirmando que produzem "saberes em diálogo", a seção pernambucana assumia discutir "História e Diversidade: Novas Narrativas, Sujeitos e Espaços", anotando, no texto de apresentação do evento, que tinha “(...) como elemento catalisador a questão da diversidade no ensino, pesquisa e extensão em História”, certa de que falava em meio "sobretudo" - atenção! - ao "contexto atual de legalização da profissão do historiador". Coube mesmo à ANPUH do Rio Grande do Norte, naquele mesmo ano, o gesto mais ousado, ao dizer que não há conhecimento histórico sem

\footnotetext{
${ }^{3}$ Os textos utilizados nesta seção foram extraídos dos websites oficiais dos eventos a que se faz referência. Os sites foram acessados em maio de 2017.

<http://www.pe.anpuh.org/conteudo/view?ID_CONTEUDO=1027>; <http://www.anpuh-sc.org.br/encontro_estadual_2010.htm>;

<http://www.encontro2012.ce.anpuh.org/site/capa>;

<http://www.ufpb.br/evento/lti/ocs/index.php/anpuhpb/XV>;

$<$ http://www.pe.anpuh.org/conteudo/view?ID_CONTEUDO=457>;

<http://rn.anpuh.org/wp/eventos/>;

<http://www.encontro2014.mg.anpuh.org/site/capa>;

<http://www.encontro2014.bahia.anpuh.org/\#>;

<http://rn.anpuh.org/wp/vi-encontro-estadual-de-historia-da-anpuhrn/>;

<http://www.encontro2016.mg.anpuh.org/>;

$<$ http://www.snh2013.anpuh.org/>;

$<$ http://www.snh2015.anpuh.org/>
} 
diálogo social em "Conhecimento Histórico e Diálogos Social”. Temas que contraditam o conceito de historiadores como distantes da sociedade como um todo.

Em 2014, foi das seções da ANPUH Rio Grande do Norte, Minas Gerais e Bahia o protagonismo de discussões referentes ao pensamento dos praticantes de História sobre ela mesma. A Bahia tratou - uma vez mais - de "Diálogos da História", com o que qualificava os diálogos mais como "empréstimos metodológicos da História com outras disciplinas", embora tivesse o cuidado de sugerir para a análise dos historiadores as “inquietações do tempo presente”. E se, novamente, a seção ANPUH - RN ousou debater tema controverso, o do "lugares dos historiadores: velhos e novos desafios", coube à seção mineira da ANPUH tema mais provocativo, a que muitos historiadores chegam a ser avessos: o do mercado de trabalho para o historiador em "Profissão historiador: formação e mercado de trabalho", tocando num dos nós górdios que carece ser desatado: o da formação dentro dos cursos! Como historiadores devem fazer se quiserem transformar o cenário da atuação profissional se não pensarem em mudanças de seus próprios cursos? A seção MG da ANPUH fazia texto de apresentação contundente.

O evento pretende discutir o processo de formação dos profissionais que atuam no campo da História, bem como os desafios do mercado de trabalho desses profissionais para os próximos anos (...) Destaca-se a discussão sobre a importância do processo de profissionalização em curso (...) No que diz respeito à formação, serão objetos de discussão as diferentes alternativas curriculares, as pós-graduações, os novos métodos de ensino da História e as suas relações com áreas correlatas. (...) No que tange ao mercado de trabalho, serão discutidas as diversas possibilidades de atuação do historiador para além da sala de aula, como sua inserção em instituições arquivísticas e de pesquisa, nos variados equipamentos culturais, nas ações referentes à preservação do patrimônio histórico, carreiras de Estado, dentre outras (...) Os desafios existentes entre o processo de formação e a inserção do historiador no mercado de trabalho estarão no centro das discussões.

Novamente, atenção: o projeto de regulamentação da profissão historiador.

Reforçando a atualidade do estado da arte das inquietações profissionais do historiador, em 2016 algumas seções da ANPUH continuavam levantando o debate. A 
seção ANPUH-MG falava em "História: tempos de crise", referindo-se a crises epistemológicas, embora cedesse espaço para mencionar os "campos de atuação do historiador" ao citar pela primeira vez abordagem recente da "história pública" que começava a ganhar projeção no plano dos debates dos praticantes da área: "pretende-se promover o debate em torno dos vários campos de atuação do historiador (ensino, pesquisa e História Pública) (...)”.

Mas não era só em eventos regionais da ANPUH que historiadores discutiam os motivos de suas angústias profissionais, pois os eventos nacionais também não esconderam o debate de dilemas e desafios.

Em 2013, reunida em Natal (RN), a entidade debatia "Conhecimento Histórico e Diálogo Social”, tema em pauta "em função da necessidade, cada dia mais evidente, de a academia estabelecer formas de diálogo com a sociedade (...)”. O evento procurava "favorecer reflexões, propostas e tomadas de decisões que evidenciem ações na formação dos profissionais de História para suas atuações nos vários espaços do meio da pesquisa e do ensino ...". Enquanto, em 2015 ainda, Florianópolis sediava o XXVIII Encontro Nacional com o tema "lugares dos historiadores: velhos e novos desafios":

(...) a temática desta edição não poderia ser mais oportuna: Lugares dos historiadores: velhos e novos desafios. Esse mote nos inspira a refletir sobre os diversos caminhos e desafios que se oferecem à produção do conhecimento na disciplina, questões sempre em pauta na ANPUH, mas, sugere também debater outros temas complexos e plenos de atualidade. Entre esses desafios atuais podemos destacar as candentes questões em torno das apropriações e usos do passado e do relacionamento da sociedade brasileira com eventos de sua história recente, em que a opinião profissional dos historiadores tem sido solicitada, o que torna urgente a reflexão sobre nosso papel social e os imperativos éticos envolvidos (...) Sem dúvida, é fundamental estimularmos o debate sobre os lugares de atuação dos historiadores que, como cidadãos e como profissionais, labutam em diferentes espaços: salas de aula, arquivos, bibliotecas, instituições culturais e de memória, organizações sociais, entre outros.

Se, por suposto, historiadores vivem uma "crise de identidade" e outra "crise de empregabilidade", levanto a hipótese de o PROFHISTÓRIA fazer sentido se pensado 
como ação da área visando lidar com aquelas crises. Entretanto, já mesmo antes da criação do PROFHISTÓRIA, cursos brasileiros agiam à sua maneira com iniciativas importantes, revisando fundamentos, revendo arranjos e práticas profissionais, agora não mais entendidas - ou desejadas - restritamente como "práticas docentes", mas, talvez, "práticas de ensino".

Dentro de seus cursos, profissionais de História já se movimentam há alguns anos.

Mesmo com boa dose de voluntarismo e ao largo do instituído - programas de cursos, conteúdos programáticos de disciplinas fixados, tradição de ênfase na pesquisa acadêmica, matrizes curriculares, ementas de disciplinas congeladas e práticas expositivistas de aula -, mesmo tendo de passar algumas vezes ao largo dessa realidade, é em cenários como estes que historiadores têm procurado encaminhar algumas providências dentro de seus próprios cursos, mesmo que não saibam quais consequências possam trazer uma guinada de perspectiva na área com relação à representação de historiadores como eruditos intelectualistas.

Quando da realização de pesquisa que fiz em 2012, à qual já me referi antes, alguns coordenadores solícitos indicavam uma percepção da necessidade de serem os cursos de História observados. Recebi apoio para a pesquisa, com coordenadores dizendo que gostariam de saber os resultados uma vez ela terminada. Coordenador do curso de História de universidade federal paulista dizia: “Inicialmente, quero destacar o quanto é relevante sua pesquisa. Precisamos ter uma fotografia de nossos cursos a nível nacional. Já expresso meu profundo desejo de conhecer o seu trabalho, na trajetória e nos resultados" (FAGUNDES, 2015, p.166/167). ${ }^{4}$. Fagundes organizava os dados coletados de pesquisa em 2012, e ponderava:

Há dados verificáveis de que em cidades de pequeno e médio portes do país há anseios - e rubricas orçamentárias - com relação a serviços de

\footnotetext{
${ }^{4}$ Não vou fazer menção ao nome do coordenador nem da faculdade e universidade a que pertenciam até então por razões de evitar que sejam reconhecidos e seus cursos revelados, uma vez que estas atividades não são comumente reconhecidas como atividades "do curso", mas "do professor". Vou colocar apenas a menção do estado em que está localizado o autor do pronunciamento, e "e-mail", se for correspondência eletrônica, e "A" quando forem dados das apresentações dos cursos - como disse em nota anterior. Todos os extratos foram retirados de FAGUNDES, 2015.
} 
natureza vária em que o formado em História poderia atuar, cidades em que muitas vezes rubricas orçamentárias para patrimônio são devolvidas por não serem usadas na falta de profissionais para fazer projetos, gerir e executar. $\mathrm{O}$ anseio e os movimentos de profissionais historiadores por práticas profissionais e atuação social - rádio, museus, centros de memória, ONGs, publicações comerciais, ação educativa não-formal, etc. - não se limitam às atividades de pesquisa e pensamento visando produção acadêmica. (FAGUNDES, 2015, p.167).

Considerações sobre a variedade de demandas sociais feitas aos cursos puderam ser constatadas. "Demandas sociais" por História são bastante mencionadas nas apresentações dos cursos e na fala de professores.

Demandas são muito caracterizadas nas apresentações dos cursos na Web: “relativas ao conhecimento histórico, voltadas especificamente para o ensino na educação básica, além de atividades culturais relacionadas com museus, preservação do patrimônio e da pesquisa histórica" [A, RN]; demandas ligadas à "cultura geral e a particularidades culturais da comunidade em que atuará" [A, RJ]; “demandas de produção, prática e difusão do conhecimento histórico e às necessidades de discussão da sociedade em geral sobre o seu trajeto histórico, suas memórias, sua relação com o passado-presente e seu patrimônio histórico-cultural" [A-RS].

(...) demandas (...) ontem mesmo fomos procurados pela União Operária. Eles querem nos mostrar as atas, as fotos e vários membros querem contar sua história... temos que dar um retorno para eles. O Morro do (...) quer guardar a memória de seus antigos moradores... temos que estar lá!!! A prefeitura local, em função de alguns trabalhos da [universidade] inseriu em sua matriz curricular uma disciplina sobre História Local. Temos que atender professores desesperados que, sem formação na área, não sabem onde encontrar essa história local (...) vamos propor um projeto de docência em conjunto com a Pedagogia (...) nunca nos trancamos na academia (...) estamos sempre voltados para a comunidade. Existimos em função dela e deixamos o academicismo só para os artigos. (E-mail, MG. FAGUNDES, 2015, p.169, grifo meu).

Há cursos de História com iniciativas exitosas, com professores que as realçam, alguns sugerindo a variedade de públicos que os cursos podem atingir. 
(...) temos um número reduzido de professores e precisamos contar com a disposição dos alunos e egressos que nos acompanham em todas as empreitadas. (...) Esse, sem dúvida, vem sendo um diferencial para o curso: gerar pesquisadores. (...) felizmente temos colaboradores fervorosos entre os egressos e alunos (...) [Há] desafios [que] são gigantescos: não há arquivos organizados, não há incentivo ao professor, não há uma historiografia mínima consolidada... tudo está por fazer. Tivemos que aprender a buscar patrocínio, parceiros e a ir para a praça, mostrar a história desta cidade. Nosso próximo passo será tentar uma coluna no jornal. Com a experiência que temos, sabemos que quanto mais falamos de história mais as pessoas se interessam (...) Já sabemos que a história não deve ficar presa na academia e que ela se torna muito... muito atraente quando encontra com a comunidade. (E-mail, MG. FAGUNDES, 2015, p.169, grifo meu).

Em forma de grupo de disciplinas que oferecem ao final certificação de “competência” para atuação na área, ou ensaiando uma habilitação em forma de Bacharelado, há cursos que estão procurando estar atentos - inserindo disciplinas nas grades curriculares - ao Patrimônio e aos Bens Culturais, agregando o setor de Memória/Patrimônio ao setor de pesquisa stricto sensu, fatos que justificam a criação de mestrados profissionais relacionados ao campo.

Professores diziam que esperavam com isso que "as instituições da área de M \& P conheçam a formação que oferecemos aos nossos alunos" (E-mail, SP, FAGUNDES, 2015, p.163). A fala do coordenador aponta a realidade consolidada sobre a formação de historiadores, mas para combinar o foco da pesquisa acadêmica com outros focos de formação, propondo provocar uma mudança da percepção: a de que historiadores são de algum modo "profissionais práticos" formados para desenvolver outras habilidades além da pesquisa especializada voltada para escrever artigos e livros especialistas que, diretamente, dizem muito mais respeito a si próprios do que a sociedade como um todo.

Outras iniciativas partem do impulso de professores e alunos recuperarem acervos, disponibilizando-os para pesquisadores da área de História ou nãopesquisadores. Há iniciativas que tomam o patrimônio e a memória como campo para formulação de pautas identitárias locais e/ou regionais, muitas vezes agregando 
membros da comunidade em que estão os cursos. Cursos identificam iniciativas públicas e particulares de preservação de memória institucional e coletiva em empresas privadas, em instituições públicas, e alguns têm disciplinas de arquivos, documentação, museus e patrimônio na grade curricular. Há, no discurso, certa consciência de que atividades voltadas para o patrimônio são legitimadoras dos cursos junto a comunidades onde convivem. "Hoje temos muitos alunos em estágio não obrigatório em bibliotecas, museus e prefeitura, além de projetos de assessoria na organização documental e preservação de fontes (...)" (E-mail, PR, FAGUNDES, 2015, p.174).

Os arquivos privados estão em expansão no Brasil, como você deve saber. Atualmente temos uma aluna engenheira (!!) que trabalha organizando o arquivo do CREA... Além de organizar o arquivo, fará um livro com imagens, daquele que as instituições gostam de fazer periodicamente para sua 'memória' institucional. Esse campo creio que ganhará com a profissionalização de historiador que está em curso (...) Experiências assim têm acontecido, não sendo a regra, claro. (E-mail, GO, FAGUNDES, 2015, p.174, grifo meu).

Havia depoimentos sobre atividades mais propriamente da área do ensino. Nela, articuladas ou não com a instituição escolar, destacam-se iniciativas que se conectam com demandas educativas nem sempre concebidas dentro da escola, embora articuladas à memória/patrimônio e à difusão de conhecimento histórico. No setor de Extensão, articulam-se atividades educativas, pesquisa e difusão, oferecendo oportunidades para alunos e egressos associá-las à Memória e Patrimônio. Cursos transfiguram atividades extensivas educativas tratando-as como atividades voltadas para suplemento do que já fazem na Prática de Ensino. “(...) O Projeto ... foi concebido como um projeto de extensão. Seu maior objetivo é aproximar a universidade das escolas de ensino médio. [...] Há, também, os Grupos de Estudo que funcionam como pontes entre a [universidade] e a comunidade". (E-mail, GO, FAGUNDES, 2015, p.176, grifo meu).

Acontecia também a aproximação da História com a área de Comunicação, com profissionais que trabalham em parceria. Atividades educativas, de extensão e de pesquisa se articulam à difusão do conhecimento histórico, mobilizando públicos e 
equipamentos. Vivemos uma situação de mercado de trabalho em profunda transformação, cuja demanda requer ora especialistas, ora generalistas. O impulso de cursos qualificados pelo padrão dominante é para formar para a prática da pesquisa especializada, com o que se generalizou a ideia de que historiadores são "grandes cabeças" fazedoras de pesquisa acadêmica... e pronto! Quando ocorre algo como depõe o professor abaixo, a regra é a de que o historiador faça alguma formação autodidata, aprenda a fazer sozinho. Cursos fazem difusão da História por meios de comunicação da universidade - as rádios e tevês educativas, em que normalmente há possibilidade de se fazer produções menos "vendidas" ao mercado. "Temos a intenção, mas nem sempre conseguimos. Já tentamos manter uma coluna em jornal diário, por exemplo, mas não foi adiante" (E-mail, GO), confessa o professor.

[Nosso] programa [de rádio] tem fluxo contínuo (...) são inserções na programação (...) com duração de 1 a 2 minutos. Professores e alunos escolhem um tema e elaboram um pequeno texto, de até 20 linhas, em seguida gravam o texto em um estúdio e em horários fixos (diariamente em três períodos), os programinhas são veiculados. (...) têm boa recepção na comunidade, que gosta de ouvir a respeito dos temas e ao mesmo tempo, torna o conhecimento histórico agradável ao público. (Email, MG, FAGUNDES, 2015, p.178, grifo meu)

É frequente o discurso sobre a participação possível de historiadores em projetos de turismo, em produtos da indústria cultural, o que é "uma possibilidade ainda muito nova de trabalho que se abre hoje aos historiadores, dada a crescente demanda social pela História" (E-mail, RS, FAGUNDES, 2015, p.177). Projetos com historiadores em assessoria/consultoria os integram à sociedade, especialmente na área de Memória e Patrimônio. "Outra parceria fundamental é a do Museu da Cidade, dirigido por outro egresso do curso. As exposições feitas com a parceria do curso aumentaram significativamente o número de visitantes no Museu (...)" (E-mail, MG), como depõe a colega. 


\section{Uma crise de identidade profissional?}

Apontados fatores contextuais presumidamente condicionantes, envoltos por declarações de princípio proferidas por historiadores acadêmicos preocupados com o estado da arte da profissão, fica sugerido que os debates epistêmicos, interna corporis, dão mais fundamentação para a perspectiva que analise o PROFHISTÓRIA como criação derivada de outras realidades não-docentes.

Uma "crise de identidade profissional" estaria acontecendo, afetada por demandas de empregabilidade e formuladas segundo redefinições de natureza epistemológica e reavaliação da dimensão da apresentação da história em face de sua dimensão de investigação. Fato que tem sido equacionado por historiadores nos termos de uma categoria-chave, quase um campo de saber, o da História Pública.

Esta crise pode ser definida por, pelo menos, duas frentes: uma crise de legitimidade, uma vez que forte concorrência de agentes do mercado tomam o passado como "business" e substituem historiadores especialistas na consulta sobre o que foi o passado e, em outra frente, numa crise de autoridade de "dizer o passado", detectada por colegas que começam a pensar na dita "public history" anglo-saxã como posto de observação do que se passa na área do conhecimento histórico. A autoridade está numa razão direta do reconhecimento público de que haja um profissional versado, mais que outros, para fazer algo ou dizer sobre algo que seja publicamente relevante.

Mas quem é o historiador, hoje? O profissional acadêmico treinado na universidade cada vez mais especializado que escreve para os pares em revistas indexadas e ranqueadas, o diletante amador que escreve em seu blog, ou o escritor leigo de história e autor de best-seller? (...) Assim também para o que entendemos por "público": os historiadores, leitores de nós mesmos, o internauta curioso do passado ou o leitor diletante, que seleciona seus livros de história com base na indicação das colunas dos mais vendidos dos cadernos de cultura? A complicar a equação, a questão da historicidade: "historiadores", "historiografia" e "audiência" não foram sempre a mesma coisa em todo lugar e em qualquer época (...) A rígida divisão a que estamos familiarizados entre produtores (homens e mulheres treinados na universidade nos fundamentos da história como ciência, no manejo de fontes e do método crítico) e consumidores de conhecimento sobre o passado se destina em alguma 
medida a salvaguardar a autonomia dos historiadores profissionais. $\mathrm{O}$ processo de ampliação vertiginosa de protagonistas e meios de circulação da história, porém, coloca em xeque aquela divisão. $O$ discurso da autoridade não cola bem no mundo real - muito menos no mundo virtual. Além disso, a web parece configurar-se numa espécie de "esfera pública" que dispensa qualquer "validação" formal ou atestado de competência para uma interpretação particular do passado. Nesse ambiente imune ao discurso da autoridade, parece crucial que os historiadores busquem não apenas o avanço do conhecimento, mas também entender como esse conhecimento vem sendo testado e negociado. (MALERBA, 2017, p.10)

Processos de politização social que ampliam a interação e as relações sóciopolíticas requerem profissionais sempre "abertos ao diálogo extra-acadêmico". E ao diálogo na escola, o que o PROFHISTÓRIA - fomentado por discussões da área do Ensino de História - possivelmente tem como postulado.

Mudam-se - com relação à formulação tradicional do profissional historiador como professor - métodos de ensino da matéria escolar História e padrões de pensamento sobre a escola, tomada como lugar cultural e político cujos sujeitos não admitem "viverem processos de ensino unilaterais que desdenhem de seus saberes prévios". (FAGUNDES, 2014, p.308). Entra em dúvida a convicção de professores como intelectuaisguias orientadores da coletividade e se encena a legítima aspiração e prerrogativa de todos para formular pensamentos sobre o passado. A "aliança estabelecida no final do século XVIII e em vigor até há poucos anos entre História e Utopia” (BODEI, 2001, p.76), que forçava certa representação missionária dos historiadores sobre si mesmos, parece finda.

(...) As pesquisas sobre como se institucionalizam cursos de História revelam como tradições intelectuais historiadoras se constituíram na experiência histórica brasileira. Daí, faz-se importante o exame de tal institucionalização dos cursos, ratificando a máxima de que "a História também tem história" e de que a identidade profissional depende de como o sujeito pôde constituir seu conjunto conceitual de percepções e interpretações sobre o passado encarnado em cursos dentro de instituições reguladoras que constrangem uma operação historiográfica. (FAGUNDES, 2014, p.311) 
Por hipótese, admitidos tais fatores de contexto agregados ao horizonte de expectativas além docência postos aos formados em História, historiadores têm discutido os dilemas da profissão, e mesmo a sobrevivência de cursos - numa situação em que certo ideal glorioso da disciplina não se consuma mais. O PROFHISTÓRIA surge neste cenário de necessidades bem pragmáticas e de debate epistemológico.

\section{E o PROFHISTÓRIA, então? O que têm feito os novos mestres e em que direção apontam}

É de se notar que os novos mestres em Ensino de História do PROFHISTÓRIA, em variados núcleos do programa, têm inserções em esferas do mercado de trabalho que não se esgotam na escola. São profissionais que, em boa parte, ligam-se a áreas do patrimônio, do audiovisual e do universo digital - que não foram aprendidas em sua formação inicial em cursos de História.

Por hipótese, se o PROFHISTÓRIA une escola - laboratório de experimentação de práticas renovadas - e universidade, promove ainda o trânsito nele de profissionais que já foram, ou estão indo, ao mercado mais amplo de atuação do historiador tomado como locus de novas experiências que não têm a escola no centro exclusivo de suas ambições e pontos de chegada.

O PROFHISTÓRIA parece estar sendo um condensador, ambiente formativo e universo conceitual atravessado por anseios profissionais, por mudanças menos aparentes. É difícil imaginar que aqueles que elaboraram o programa não tenham pensado em algum momento que seria um tanto inoperante formar novos professores para uma escola que não consegue acolher demandas novas, ou que só formando novos professores uma nova história escolar viria à tona.

Tomei uma amostra das 24 primeiras dissertações dos PROFHISTÓRIAS postadas no site do PROFHISTÓRIA nacional ${ }^{5}$ (<https://profhistoria.ufrj.br/>). O critério da escolha

\footnotetext{
${ }^{5}$ Em 10 de junho, estavam postadas 47 dissertações. Foram analisadas as 24 primeiras dissertações, com consulta ao resumo do trabalho e currículo Lattes do discente que se tornou mestre, e também do (a) docente que o orientou. A intenção principal era verificar não só a natureza da dissertação, mas se
} 
foi aleatório em função do tempo da escrita do artigo e aproveitando os textos naquele momento postados na Web. Na convicção que dali - o que se mostrou factível - seria possível verificar amostra significativa das dissertações das quais seriam retiradas apreciações relativamente à composição da relação orientador e orientando articulados ao trabalho que fizeram.

Num circuito de trocas expressas em fatores envolvidos por itens de um contexto de expectativas de mudanças e revisão conceitual da identidade da História, em que a História é forçada a dialogar com uma cultura histórica que não dispõe de um paradigma totalizante (SARLO, 2007) e encontra conforto nas memórias que lhe são vendidas num mercado simbólico, a criação do PROFHISTÓRIA provavelmente emanou de fatores, hipoteticamente, de cuja consciência seus elaboradores não a haviam percebido como “consciência filha de um tempo", seja da história da História, seja de demandas públicas por História que forçam cursos de História a se reverem.

As dissertações dos primeiros mestres em Ensino de História formados nos núcleos do PROFHISTÓRIA revelam um arco de maior amplitude de formação e atuação, com a constatação de que seus praticantes são professores sim, mas professores, também, com outro perfil e com uma extensão inequívoca a universos de inserção que não se limitam à escola formal, e com habilidades diversas das habilidades expositivistas que, em longa tradição, identificam conhecimento e ensino segundo práticas universais consagradas e cristalizadas - únicas capazes de qualificar alguém como “professor”.

Mesmo se não questionando a estrutura escolar, o PROFHISTÓRIA, embora explicitando a profissionalização do professor como seu objetivo, ao trazer para a formação continuada professores de agora, termina por lidar com profissionais que demonstram terem sido sensibilizados e estão combinando a escola e as habilidades para ser professor com práticas e habilidades provindas de relação com universos nãoescolares, descentralizando a escola do papel de único lugar de aprendizagem histórica. O PROFHISTÓRIA parece supor um profissional professor sensível, ao mesmo tempo que habilidoso para tarefas e atividades de outra escola a ser igualmente transformada.

discente e docente possuíam inserções em trabalhos de História em lugares de memória que não são a escola. 
Mercado tomado como universo de experimentos e escola tomada como universo em que se adotam práticas extraescolares nas quais se aprende pela mão de mestres em Ensino Profissional de História, a escola que supõem é muito mais permeável a um rol de influências públicas diversificado.

Resultam muitas daquelas dissertações de novas inserções profissionais e itinerários de formação não-convencionais. Inserções, é bom que se frise, não só dos discentes, mas dos docentes também, num mercado que envolve escola, universidade, negócios e autoridade científica. Têm sido comuns professores que transitam em áreas e não só transitam: mas que têm, ou um dia tiveram - vínculos formais com áreas públicas ou privadas que envolvem patrimônio, produção de documentários e filmes, produtos do universo digital.

Metodologicamente, boa parte das dissertações apresentam-se como resultado de produção de "material instrucional" que provêm de construção de sites, blogs, documentários digitais, muitas vezes saudavelmente dispostos a entregar prontos aos estudantes de escolas (colegiais), mas muitos confeccionados por eles, a fim de fazê-los participarem da "construção da história", conhecendo-a mais assim. Jogos físicos, mas também jogos mediados pelo digital, com construção de blogs de interação, uso de Whatsapp como plataforma de aprendizagem, agregam e facilitam um trabalho conjunto mediado pela tecnologia.

É visível a índole com relação à aprendizagem que significa fazer os alunos de escola sentirem na história uma dimensão prática, em que a teoria vai oculta, sem embaraçar ou inflar o conhecimento histórico como conhecimento que enfade, só critique ou só conteste, e que, pelo contrário, ao fazer, também divirta, entretenha ou dê prazer.

É preciso discutir com seriedade o que Albuquerque Júnior (2012) propõe ao afirmar que a História não é para desalienar, ou Marc Bloch, quando postula que ela mesma pode e deve divertir, falando não só a especialistas, mas também a escolares. A adesão a um princípio glorioso e auto-edificante de história como cultivo e colheita de consciências justas e críticas parece dar lugar a um princípio mais chão, mais comum, 
ajustado a uma noção de consciências críticas forjadas na criatividade - como parece estar no pensamento de muitos mestres que defenderam suas dissertações no PROFHISTÓRIA, fazendo jogos, documentários, games, guias, mapas, dossiês fotográficos.

A História Cultural ensinou-nos a dificuldade de conhecer o universo deslizante da recepção, da apropriação/elaboração do conhecimento quando acionado por práticas diversas de ensino-aprendizagem. Assim nos ensinam as análises sob o aporte teórico da História Cultural, como quer Fonseca (2011, p.18). Os mestres do PROFHISTÓRIA, ao fazerem o que fazem com o pensamento em alguns efeitos que possam gerar, talvez não saibam que estejam gerando efeitos em que não pensavam antes. É um inferência, uma hipótese a se verificar com os mestres propriamente em pesquisa futura.

Patrimônio, educação patrimonial ou patrimônio histórico-cultural têm tido muita entrada nas dissertações, muitas vezes para inventariar saberes de culturas locais, próximas das comunidades tocadas pelas escolas. Docentes orientadores envolvidos em grupos de pesquisa na universidade que desenvolvem material instrucional para o trabalho com o patrimônio, e discentes que têm, ou já tiveram, vínculos com órgãos municipais ou estaduais de patrimônio, ou que estão, ou um dia estiveram, em projetos desta natureza. Por trás da preocupação com a identificação afetiva e sentimental com o que é próprio, patrimônio do estudante, há a oferta de um espaço criativo para ele fazer seus juízos, inscrever suas ambições e percepções, que, na área do patrimônio, muitas vezes não é o patrimônio oficializado. Destacam-se as temáticas da História da África, Cultura Afro-brasileira, Cultura Indígena, certamente em virtude da adoção do Ensino de História da Cultura Afro-Indígena brasileira.

Ressalta-se ainda sensibilidade dos mestres quanto ao saber histórico prévio do estudante da escola, saber aprendido em outros meios, espaços de memória que os mestres do PROFHISTÓRIA não desdenham, mas aproveitam como material indispensável de aulas e atividades. São filmes de animação, museus, cinema, literatura, internet.

Da parte dos (as) professores (as) orientandores (as), verifica-se que mostram mais que uma inclinação, mas se fazem já identificados com práticas de historiadores que 
não se restringem à escola, mas com práticas de outros lugares que podem se combinar com as da escola, pela via, talvez, da difusão - onde se destaca a Web como plataforma de atuação, mas não só. Em sua grande maioria professores estão participando, sem constrangimento, de rádio e de televisão - programas de entrevistas, mesas-redondas, textos de informação histórica e popularização de ciência, sem caírem na dúvida existencial se estão piorando a História fazendo assim. Afinal, a difusão do conhecimento histórico se faz por vários meios, e se dispositivos como a Web, rádios, televisão, reivindicam-no, não há por que se recusar, condenando essas práticas e lugares de memória de antemão como inadequados ao que seria o "bom conhecimento histórico" acadêmico.

Docentes prestam consultorias e assessorias, mesmo para memórias empresariais. Mesmo se se julgar que haja nisso um componente lucrativo condenável, antes disso seria importante se julgar se um componente provável de mudança de identidade profissional, diversificando campos de atuação, métodos de ação práticas de intervenção social e de reconhecimento de que esses são modos de legitimação social que não podem ser desprezados. O historiador que se abstém, ou se isenta de participar desses "outros espaços de atuação", não tem sido o usual entre docentes do PROFHISTÓRIA e entre seus (suas) orientandos (as). Muitos docentes do programa provavelmente já estiveram em iniciativas e realizações da natureza similar às que aparecem nas dissertações de seus orientandos. A verificação foi feita em consulta de seus currículos Lattes.

Conferindo alguma pertinência com que levanto como hipótese aqui - a de que o PROFHISTÓRIA refere-se à realidade já existente antes - é relevante que muito material que está sendo produzido por professores mestres com suas dissertações defendidas esteja caminhando no mesmo sentido do que cursos já faziam e mesmo com relação a que documentos públicos referem-se como práticas atuais de historiadores que, segundo a justificativa do PL da regulamentação, “hoje já não se limitam a docência”. Ao ser criado, o PROFHISTÓRIA confere certo verniz de institucionalidade ao que cursos de História já faziam e de anseios manifestos de pretendentes a áreas de História que não pretendem a docência como destino profissional. 


\section{Palavras finais - uma atitude nova e os anseios por mudanças}

Estou querendo argumentar que o PROFHISTÓRIA, criado em 2013, resulta de um movimento intenso por dentro da seara historiadora, adotando o procedimento de levantar hipóteses para um processo em que, muitas vezes, o sujeito não tem plena consciência do para que está fazendo. É assim que me parece todo esse conjunto de fatos e fatores, vistos como condicionantes e influentes da criação do programa.

Visto por meio de suas primeiras dissertações, é de se realçar o perfil dos mestres dos núcleos do PROFHISTÓRIA, sua versatilidade e para que direção apontam suas ideias, percepções e concepções de escola - com o que se pode perguntar, em duas direções. Numa, como querer acionar e/ou encaminhar mudanças em meio a estruturas escolares tão rígidas, expectativas sociais cristalizadas pelo conhecimento histórico que a escola ensina, e assim sonhar com transformações que o PROFHISTÓRIA possa vir a ocasionar. Pensar o PROFHISTÓRIA como incubador de transformações sociais pelo que ensinam os novos mestres sem se considerar uma transformação simultânea da escola seria uma utopia! Noutra direção, parece-me razoável aceitar que o PROFHISTÓRIA tem precedentes enraizados na escola e em cursos de História antes dele, e que provêm do mesmo fundo comum de insegurança e ansiedade quanto a questões não só paradigmáticas e epistemológicas, mas questões bastante pragmáticas ligadas ao destino da profissão expressas pela baixa procura de seus cursos e questões de empregabilidade na área.

De algum modo, o PROFHISTÓRIA acolhe paradigmas novos, supõe funções da História flexibilizadas, distantes do emblema oitocentista de "formar cidadãos críticos e participativos", 6 normalmente associada a práticas didáticas de atuação profissional prescritas com um fundamento moral irreprimível.

Iniciativas como os mestrados profissionais, projetos como o da criação do profissional historiador, o Programa de Iniciação à Docência (PIBID), somam-se a ações em cursos de História, ainda que com alguma dose de aleatoriedade e experimentação, que tentam equacionar dilemas derivados de realidades novas, induzindo outra relação

\footnotetext{
${ }^{6}$ A menção ao slogan provém de CARDOSO, 2007.
} 
da universidade histórica com a escola revista e rediscutida, tomada como locus de um público gigante de 50 milhões de pessoas.

Boa parte dos historiadores lançam sinais de que já percebem que precisam se atualizar quanto à sua participação social e política, abrir-se ao diálogo e a interação extra-acadêmica, e já o fazem sem prever quais as utilidades de suas práticas reformadas. Numa época em que a história e a memória nunca estiveram tão em voga, a realidade anda a exigir crítica e verificações. O historiador reitera o princípio que fundou sua formação, mas não sabe exatamente como fazer para atualizá-la aos tempos de hoje.

Duas dimensões da questão parecem-me cruciais.

Como lidar com essa mutação do estatuto de valor do passado e como lidar com os próprios cursos de História, que são organizações sociais em que se fixam abordagens e teorias da História, o perfil de quem é o historiador e uma auto-representação sobre o papel do historiador e sua atuação na sociedade.

Ao mesmo tempo em que conscientes de seu papel de vigilantes da interpretação do passado a partir de um conhecimento consolidado, historiadores patinam na hora de saberem como se ajustar - mesmo que atuando criticamente - a realidades em que se veem vencidos pelo desinteresse de sua produção em meio ao interesse do público mais cativo de escolares por História em outros meios e suportes. Beatriz Sarlo analisa a concorrência entre produtos acadêmicos e não-acadêmicos de História.

Nessa concorrência, a história acadêmica perde por motivos de método, mas também por suas próprias restrições formais e institucionais, que a tornam mais preocupada com regras internas do que com a busca de legitimações externas que, se são alcançadas por um historiador acadêmico, podem até originar a desconfiança de seus pares. As histórias de grande circulação, em contrapartida, reconhecem na repercussão pública de mercado sua legitimidade. (SARLO, 2007, p.14-15)

É importante ver que historiadores têm percebido que influenciar a sociedade, falar a ela, é mais do que necessário. 
A questão envolve reencontrar um lastro de legitimidade que recupere a autoridade científica de dizer a história em disputa com a autoridade que agentes em outros meios e suportes têm conseguido, legitimados por dispositivos de mercado chancelados por uma memória coletiva que os aceita e a qual oferece consolo sem exigir crítica, nem participação social. Resgatar a legitimação que durante mais de um século garantiu a autoridade de historiadores quanto ao conhecimento e difusão da História, criando memórias, é parte de um processo político e social que não pode ficar fora da concepção de nossos cursos. Ainda como sugere Sarlo, legitimações externas aos departamentos de História são indispensáveis. Ao trazer alunos (as) cujas atividades contam com razoável interface com práticas sociais, e que valorizam o saber dos estudantes de escola, o PROFHISTÓRIA favorece aquelas legitimações externas.

Fazendo com que componentes da produção histórica extra-acadêmica cheguem até ela pelas mãos de seus professores-mestres formados pelo PROFHISTÓRIA devidamente reconhecidos pelos alunos da escola, ela provavelmente aponte um caminho. Um caminho que requer rever a política que organiza a autoridade de formados em História na universidade e as fontes de suas legitimações - e o papel que cabe aí à História matéria escolar.

Historiadores profissionais dentro das universidades parecem estar se perguntando isso, e a primeira constatação saudável a que se chega é a de que, de alguma forma, devemos participar do processo de disseminação de nossas pesquisas para um público maior do que nós próprios. Como fazer sem que isso prejudique um conhecimento consolidado e suficientemente sólido revestido de consistência teórica e proposições que não se curvem ao sensacionalismo, à diversão fácil - aceitas e, na maioria dos casos, apoios de discursos que ocultam domínios e sedimentam tradições historicamente excludentes - eis a questão-chave.

É assim que o PROFHISTÓRIA aparece, sem se saber direito aonde vai chegar e o que exatamente mobiliza a vontade de seus propositores, embora o artigo $1^{\circ}$ de seu regimento seja imperativo ao regrar, supostamente, o que consubstancia o que quer: “dar ao egresso qualificação certificada para o exercício da profissão de professor de História”. Os cursos de graduação já certificam para essa qualificação. Organismo vivo, 
repleto de demandas diversas, a escola é - ou deveria ser - laboratório de experimentos e promotora de novas expectativas sociais. Mas, suposto que o programa não discuta a escola e suas estruturas, as expectativas sociais do que a escola em tese seria capaz de realizar, fica a pergunta sobre o que o PROFHISTÓRIA pode oferecer de tão renovador. A hipótese que levanto é a de que a relação escola e sociedade, cultura histórica acadêmica e escolar se estreitam quando o PROFHISTÓRIA faz o que faz, realiza o que realiza.

O PROFHISTÓRIA talvez pretenda muito menos do que pretendi hipoteticamente cogitar aqui. No entanto, fatos de um contexto maior que o abraçam permitem pensar no programa como algo que extrapola o diagnóstico da relação escola-universidade e extravasa para o diagnóstico da relação da História com outros públicos sociais e suas legitimações extra-departamentais.

Pelo sim, pelo não, é tempo de experimentar, como professores já têm feito dentro de seus cursos. O PROFHISTÓRIA é uma aposta, um experimento de diagnóstico mais bem formado, mas de prognóstico indefinido, haja vista o futuro da profissão e mesmo dos cursos de História, uma vez que dependem de muitos mais fatores para além dele mesmo, ou do que um curso de formação pode oferecer. No mínimo podemos cogitar que ele organiza uma sensação de que algo está sendo feito na e pela área ante uma situação de crise, propondo novidade. Isso não deixa de ser um alento, um fôlego novo para se enfrentar os desafios mais angustiantes que atingem emcheio a identidade e mesmo sobrevivência profissional.

Daquele algo podem vir mais criações e tomadas de decisão importantes para além do universo escolar, inclusive, afinal as práticas adotadas nas escolas e experimentadas pelos mestres do PROFHISTÓRIA demonstram que elas estão bem mais pulverizadas socialmente e não se circunscrevem ao cotidiano escolar.

O programa acolhe expectativas e anseios dispersos por alguma atitude de mudança de postura e ele talvez esteja sendo reconhecido como um primeiro passo em direção a resultados sem prognósticos previstos. No mínimo, a criação do PROFHISTÓRIA tem posto na agenda do debate a questão das vantagens e desvantagens da História para a sociedade e que há razoável responsabilidade dos historiadores com relação à área, aos 
quais respondem com a criação de um programa sob o argumento da premência do "algo tem de ser feito".

O PROFHISTÓRIA pode vir a atender anseios por cenários profissionais mais promissores e motivadores, o que, porém, só o tempo dirá se serão alcançados.

\section{Referências}

ALBUQUERQUE JUNIOR, Durval Muniz de. Fazer defeitos na memória: para que servem o ensino e a escrita da História? In: GONÇALVES, Márcia de Almeida et al (Orgs.). Qual o valor da História hoje? Rio de Janeiro: FGV Edit. 2012.

AMORIM, Marina. Histórias de jovens profissionais da História: trajetórias de egressos do curso de História da FAFICH/UFMG (1998/01). Educação em Revista, Belo Horizonte, v.30, n.04, p.37-59, out./dez., 2014.

BODEl, Remo. A História tem um sentido? Bauru, SP: EDUSC, 2001.126 p.

BRASIL, Senado Brasileiro, 2012. PARECER N , Da COMISSÃO DE ASSUNTOS SOCIAIS, em decisão terminativa, sobre o Projeto de Lei do Senado $n^{\circ} 368$, de 2009 , do Senador Paulo Paim que regula o exercício da profissão de Historiador e dá outras providências.

Disponível em http://legis.senado.leg.br/sdleg-

getter/documento?dm=4351287\&disposition=inline. Acesso em maio de 2011.

CARDOSO, Oldimar Pontes. A didática da história e o slogan da formação de cidadãos. São Paulo, 2007. 250 f. Tese (Doutorado em Educação) - Universidade de São Paulo, Faculdade de Educação.

FAGUNDES, Bruno Flávio Lontra.; HAHN, Fábio A. História e realidades on line: colocações sobre produção, difusão e ensino - BRUNO LEAL. Revista NUPEM, Campo Mourão, v.6, n.10, p.11-25, jan.;jun., 2014.

FAGUNDES, Bruno Flávio Lontra Entre tradição, inovação e renovação: sobre cursos de história brasileiros. Revista Saeculum - Revista de História, João Pessoa, n.32, p.159-181, jan.junho 2015.

FAGUNDES, Bruno Flávio Lontra. História, historiador e identidade profissional: sobre a história do Curso de História da Universidade Federal do Paraná. Revista Estudos

Históricos, Rio de Janeiro, v.27, n. 54, p. 295-315, jul./dez., 2014. 
FIGUEIREDO, Luciano. Entrevista de Luciano Raposo de Almeida Figueiredo. Revista Mosaico, v.2, n.30, 2010. Disponível em <file:///C:/Users/Bruno/Downloads/64380-135939-1PB\%20(1).pdf>. Acesso em maio de 2011.

FONSECA, Thais Nivia de Lima e. História \& ensino de história. 3. ed. Belo Horizonte: Editora Autêntica, 2011.

LEME, Luciana França. A atratividade do magistério para a educação básica: estudo com ingressantes de cursos superiores da Universidade de São Paulo. São Paulo, 2012. 210f. Dissertação (Mestrado em Educação) - Universidade de São Paulo, Faculdade de Educação, 2012.

MALERBA, Jurandir. Ser historiador no Brasil no século XXI. In: Café História, blog temático, 2012. Disponível em: <http://cafehistoria.ning.com/>.

MALERBA, Jurandir. Os historiadores e seus públicos: desafios ao conhecimento histórico na era digital. Revista Brasileira de História, v. 37, n.74, p. 135-154, 2017.

SARLO, Beatriz. Tempo passado: cultura da memória e guinada subjetiva. Belo Horizonte; São Paulo: Ed. Da UMFG: Cia das Letras, 2007.

SOUZA, João Valdir Alves de Souza. Quem ainda quer ser professor? Boletim UFMG, n.1755, ano 38, 31 de out., 2011. Disponível em:

<https://www.ufmg.br/boletim/bol1755/2.shtml>. Acesso em maio 2017.

Recebido em: 13/07/2017

Aprovado em: 30/11/2017

Universidade do Estado de Santa Catarina - UDESC Centro de Ciências Humanas e da Educação - FAED

Revista PerCursos Volume 18 - Número 38 - Ano 2017 revistapercursos@gmail.com 